\title{
AVALIAÇÃO DE PROPRIEDADES MECÂNICAS DA MADEIRA DE Eucalyptus urograndis SECOS
}

\author{
João Marcelo Soares Pereira' ${ }^{1}$ \\ Giovanni Mendes Satler ${ }^{2}$ \\ Julião Soares de Souza Lima ${ }^{3}$ \\ Pedro Gutemberg de Alcântara Segundinho ${ }^{4}$
}

Resumo: O presente trabalho teve como objetivo avaliar as propriedades mecânicas de cisalhamento e compressão de corpos de prova de Eucalyptus urograndis secos. Os seis corpos de prova utilizados no estudo foram retirados de peças de calços com quatorze anos de idade, para cada ensaio mecânico: cisalhamento ( $f v 0)$, compressão paralela às fibras ( $f c 0)$ e normal às fibras ( $f c 90)$. Os valores médios de resistência obtidos nos ensaios de cisalhamento, compressão paralela às fibras e normal às fibras foram 10,30 MPa, 59,17 MPa e 9,20 MPa, respectivamente. Todos os valores obtidos alcançaram valores médios acima da referência estabelecidos pela NBR 7190 (1997).

Palavras-chave: Cisalhamento; Compressão paralela; Compressão normal; Eucalyptus urograndis.

\footnotetext{
${ }^{1}$ Engenharia Civil/Universidade Federal do Espirito Santo, Brasil. E-mail: jmsoarespereira@hotmail.com.

2 Engenheiro Florestal/Universidade Federal do Espírito Santo, Brasil. E-mail: giovanni.satler@hotmail.com.

${ }^{3}$ Engenheiro Agrícola/Universidade Federal do Espírito Santo, Brasil. E-mail: limajss@yahoo.com.br.

${ }^{4}$ Engenheiro Civil/Universidade Federal do Espírito Santo, Brasil. E-mail: p_gutemberg2001@yahoo.com.br.
} 